\title{
Antiplasmodial and in vitro antioxidant potentials of crude aqueous and methanol extracts of Chasmanthera dependens (Hochst)
}

\author{
Conrad Kenechukwu Enenebeaku', Cynthia Ekwy Ogukwe', Christian Okechukwu Nweke², \\ Sylvia Onyinyechi Anyado-Nwadike ${ }^{3}$, Martin $\mathrm{Obi}^{4}$, ljeoma Akunna Duru?', \\ Uchechi Emmanuela Enenebeaku ${ }^{3^{*}}$ and Odangowei I. Ogidi ${ }^{5}$
}

\begin{abstract}
Background: Malaria is a major cause of death in tropical countries such as Nigeria. Chasmanthera dependens (Hochst) is a wild plant used by traditional healers for the treatment of malaria and other health challenges. This study evaluated the 'Antiplasmodial and in vitro antioxidant potentials of crude aqueous and methanol extracts of leaves, root and stem of Chasmanthera dependens (Hochst)'.

Results: Methanol extracts of leaves and roots of this plant exhibited higher antimalarial activities than other extracts. The level of parasitemia was significantly $(p<0.05)$ reduced in the treated animals when compared to untreated ones. Antiplasmodial activities of methanol extracts of roots and stem did not differ significantly $(p<0.05)$ from their aqueous extracts. An increase in body weight and higher survival rates were recorded in all the treated groups. Scavenging of DPPH, NO, $\mathrm{H}_{2} \mathrm{O}_{2}$ radicals and reducing power ability were concentration-dependent. Methanolic extracts of $\mathrm{C}$. dependens root showed the best reducing activity. Phytochemical analyses revealed the presence of tannins, saponins, alkaloids, terpenoids, cardiac glycosides, flavonoids, phenols, phytate and oxalate.

Conclusion: Antimalarial and antioxidant properties of these extracts could be credited to the synergy between the phytoconstituents in this plant. Findings from this study justified the use of this plant in the treatment of malaria and other ailments.
\end{abstract}

Keywords: Chasmanthera dependens, Mice, Plasmodium berghei, In vivo study, Antimalaria

\section{Background}

Malaria has been implicated as a major reason for the sickness and death of about two million infants worldwide annually (Okafor and Oko-Ose 2012). Globally, this disease has a higher death rate than other infectious diseases (World Health Organisation 2015). It is common in the poor, less-developed countries of the world and

\footnotetext{
*Correspondence: ucheodionye@yahoo.com

${ }^{3}$ Department of Biotechnology, Federal University of Technology Owerri, Owerri, Nigeria

Full list of author information is available at the end of the article
}

widely spread in tropical countries such as Nigeria (Okafor and Oko-Ose 2012).

About $92 \%$ of pregnant women and infants less than 5 years of age are very prone to malarial attacks due to their lowered immunity (Adebayo and Kareth 2010).

Treatment of this parasitic disease still relies on the administration of drugs whose efficacy is constantly frustrated by the continuous appearance of resistant strains of the parasite, coupled with the high cost of these orthodox drugs. Consequently, many caregivers, herbal homes and traditional medicine practitioners resort to the use of various traditional herbs and plants in the management of malaria. Herbal or traditional medicines are the first 
form of treatment given to many patients with suspected symptoms of malaria, especially in tropical countries, such as Nigeria, Ghana, Mali and Zambia (David et al. 2014). It is general knowledge that plants are the origin of some known orthodox antimalarial drugs such as quinine and artemisinin derivatives (Mustofa et al. 2007). It is therefore imperative to scientifically investigate the antiplasmodial potentials of these traditional plants, which might become sources of new antimalarial drugs.

Antioxidants are substances that prevent cells from being damaged by the effects of Reactive Oxygen Species (ROS) known as 'free radicals.' They have sufficient electrons which they easily donate to compounds or molecules that are electron-deficient. These electron-deficient compounds have unpaired valence electrons (Aluko et al. 2013). In the bid to get more electrons, they may attack cells or biomolecules in the human body resulting in the generation of many diseases (Aluko et al. 2013). As they get sufficient electrons, their actions are stabilized. An imbalance between antioxidants and Reactive Oxygen Species could result in oxidative stress and cellular damage. According to studies by Uddin et al. (2018) and Jayasri et al. (2019), natural antioxidants serve the purpose of maintaining good health and well-being, as well as prevention of chronic and degenerative diseases, such as cardiac and cerebral ischemia, atherosclerosis, neurodegenerative disorders, carcinogenesis, rheumatic disorder, damage to DNA and aging.

Chasmanthera dependens (Hochst) is a flowering plant of the Menispermaceae, commonly called Chasmanthera (Fig. 1). It grows around forest margins, savannah or secondary forest. It thrives in moist and dense evergreen forest and grows up to $1500 \mathrm{~m}$ preferring well-drained soils. Usually, it is intentionally cultivated in homes or gardens as a medicinal plant. It is called 'aguru' in Igbo (SouthEast Nigeria), and 'atoo' in Yoruba (South West Nigeria).

It has been used in the treatment of health problems such as red-eye infections (Ogunlesi et al. 2008); veneral diseases, convulsions, snakebites, epilepsy, and in the management of fractures (Ogunlesi et al. 2008). It is also useful in controlling physical and nervous weaknesses (Iwu et al. 1999). According to Morebise et al. (2001), methanol extract of the dried leaves has anti-inflammatory and analgesic properties. Similarly, Adekunle and Okoli (2002) have reported antifungal effects of crude aqueous and ethanol extracts of the leaves. Antimicrobial activities of $C$. dependens stem on fungal yeast, Gram+ and Gram- bacteria were reported by Githinji et al. (2010). In vitro, antileishmanial and immunomodulatory activities of $C$. dependens stem and leaves were reported by Iwu et al. (1999). Aqueous extract of Chasmanthera dependens roots demonstrated pro-spermatogenic, fertility-enhancing, and androgenic activities in male rats

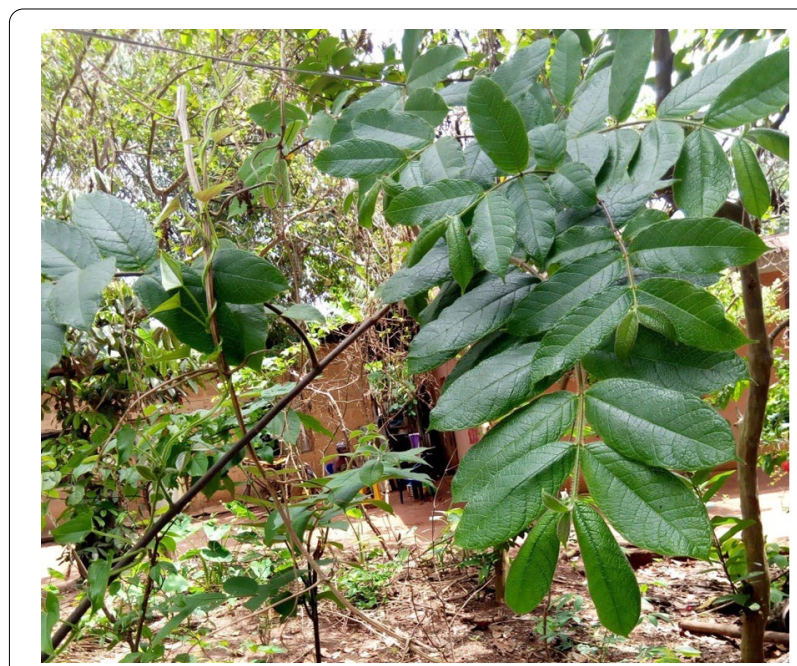

Fig. 1 Chasmanthera dependens

(Quadri and Yakubu 2017). However, the antimalarial and antioxidant activities of this plant are unavailable in the literature.

This study, therefore, evaluated the antimalarial and in vitro antioxidant potentials of aqueous and methanolic extracts of leaves, stem and roots of the plant.

\section{Methods}

\section{Sample collection and identification}

Fresh leaves, stems and roots of Chasmanthera dependens used in this study were collected from a fallow farmland at Ahiazu Mbaise L.G.A of Imo State, located between latitude $5^{\circ} 19^{\prime}$ and $5^{\circ} 32^{\prime} \mathrm{N}$ and longitude $7^{\circ} 12^{\prime}$ and $7^{\circ} 20^{\prime} \mathrm{E}$ (Ifeanyichukwu et al. 2016). They were transported to the laboratory where they were verified and authenticated by a taxonomist in the Department of Biological Sciences, Federal University of Technology, Owerri, Nigeria, with voucher number FUTOH- 006. The plant parts were sliced to reduce their size, air-dried at room temperature and pulverized using a laboratory mill. The coarse powder was then sieved, using a $2 \mathrm{~mm}$ mesh sieve, to obtain smooth samples.

\section{Preparation of extracts}

Using cold maceration, $200 \mathrm{~g}$ of each powdered plant material was separately soaked in $1000 \mathrm{ml}$ of distilled water to get the aqueous extract. Samples were macerated for $48 \mathrm{~h}$ as described by Ene et al. (2013).

Methanol extraction was done according to Dejen et al. (2018). Two hundred (200 g) grams of the various plant materials were extracted with $1000 \mathrm{ml}$ of $80 \% \mathrm{v} / \mathrm{v}$ methanol solvent using soxhlet extraction. After extraction, both aqueous and methanol extracts were filtered, 
using a clean muslin cloth and Whatman number 1 filter paper to remove residues. Filtrates were concentrated and dried using a rotary evaporator (RE- 52A, Searchtech Instruments) set at a temperature of $50{ }^{\circ} \mathrm{C}$ to remove the solvent. Extracts were weighed and stored in well-labeled bijou bottles and kept at $4{ }^{\circ} \mathrm{C}$ in a refrigerator until needed.

\section{Phytochemical screening}

Crude aqueous and methanolic extracts of leaves, root and stem of $C$. dependens were screened for the presence of phytochemicals using standard methods (Trease and Evans 1989; Harborne 1973; Sofowora 1993).

\section{Animal grouping}

Fifty-four (54) male Swiss albino mice of 18-25 g weight were used for this study. They were obtained from the animal house of Veterinary Medicine, University of Nigeria, Nsukka. They were kept in animal cages in the laboratory environment for 14 days with feed (rat pellets) and water ad libitum and monitored under 12 -h, light and dark cycles, in well-aerated cages. They were then separated into 9 groups of 6 mice each according to their body weights. On the basis of their position on the rack, cages were given numerical designation. For each treatment group, a cage was selected randomly from the pool of cages. The cages were then randomized within the treatment group. Animals in each group were assigned marks on different parts of their bodies using picric acid for easy identification. The cages were then randomized within the treatment group. Animals were grouped and treated as follows: Group 1- feed and water (normal control group), Group 2- artesunate (standard control group), Group 3- negative control, Group 4- methanolic extract of Chasmanthera dependens root, Group 5- methanolic extract of Chasmanthera dependens leaves, Group 6methanolic extract of Chasmanthera dependens stem, Group 7- aqueous extract of Chasmanthera dependens root, Group 8- aqueous extract of Chasmanthera dependens leaves, Group 9- aqueous extract of Chasmanthera dependens stem. The study was carried out with ethical approval obtained from the Department of Biochemistry, Federal University of Technology, Owerri, with the reference number-FUTO/BCH/DEC/XXI/03/01.

\section{In vivo culture of $P$. berghei}

Before the experimental animals were inoculated with the infected blood, parasitized blood from a donor mouse was first diluted with normal saline as described by Kabiru et al. (2012). This innoculum was prepared such that each $0.2 \mathrm{ml}$ contained approximately $1 \times 10^{7}$ parasitized erythrocytes. The animals were then injected with $0.2 \mathrm{ml}$ of this suspension through the intraperitoneal route. Animals in groups 2-9 were inoculated with chloroquine-resistant Plasmodium berghei (NK65) on day zero $\left(D_{0}\right)$ through the intraperitoneal route.

\section{Treatment of infected mice}

A standard 4-day curative test of David et al. (2004) and Peter and Anatoli (1998) was used for the in vivo antimalarial test. Only animals with percentage parasitemia of $60 \%$ or more were included in the treatment groups. Animals whose percentage parasitemia were below $60 \%$ were excluded in the treatment groups. Animals in group one were not infected with the parasites, while animals in groups two to nine were infected with Plasmodium berghei. Seventy-two hours (72 h) after infection, animals in the treatment groups (2-9) were orally given $200 \mathrm{mg} / \mathrm{kg}$ body weight of the standard antimalarial drug (artesunate) and $200 \mathrm{mg} / \mathrm{kg}$ body weight of the extracts once daily for 14 days. A dose of $200 \mathrm{mg} / \mathrm{kg}$ body weight was administered based on the result of the acute toxicity test which was earlier determined to be $5000 \mathrm{mg} / \mathrm{kg}$ body weight for the crude aqueous and methanol extracts of the leaves and roots and less than $3808 \mathrm{mg} / \mathrm{kg}$ body weight for the methanol and aqueous extracts of the stem of this plant. Treatment was administered based on the average body weight of the animals. The untreated control group received no treatment. The extracts were redissolved in distilled water to the required dose level. Parasitemia was accessed in all the groups on day 7 (4 days after treatment) and day 14 (7 days post-treatment) as described by Kabiru et al. (2012) and results were compared with the untreated group. Blood smears obtained from a cut on the tip of the tail of the mice were fixed for $15 \mathrm{~min}$ with methanol, Giemsa-stained for $25 \mathrm{~min}$, washed off with phosphate buffer ( $\mathrm{pH} 7.2)$, dried and viewed under the light microscope (magnification $=\times 100$ ) under a drop of immersion oil to determine parasitemia count. Percentage parasitemia in treated animals was determined as outlined by Iwalewa et al. (1997):

$$
\% \text { Parasitemia }=\frac{\text { No. of Parasitemia in treated }}{\text { No. of Parasitemia in control }} \times \frac{100}{1}
$$

\section{Euthanization of animals}

At the termination of this experiment, animals used for the study were euthanized following the procedure described by Moody et al. (2014). They were kept in a transparent perspex chamber and euthanized with slow rising concentrations of carbon dioxide using a gradual fill (30\% chamber volume per minute) technique. These animals were monitored closely till they lost consciousness.

In this experiment, three different investigators were involved as follows: the first investigator administered the 
treatment based on the randomization table. This investigator was the only person aware of the treatment allocation. A second investigator unaware of the treatment was responsible for checking the toxicity and parasitemia level, while a third investigator was responsible for the euthanization procedure.

\section{Determination of radical scavenging activity against 2,2-diphenyl-1-picryihydrazyl (DPPH)}

The method of Lim and Quah (2007) was used to determine the free radical scavenging activity of the plant extracts against 2,2-diphenyl-1-picrylhydrazyl radical. Various concentrations of the extracts $(0.5,1.0,1.5,2.0$ and $2.5 \mathrm{mg} / \mathrm{ml}$ ) were mixed vigorously in $5 \mathrm{ml}$ of DPPH solution $(0.1 \mathrm{mM}$ in methanol) in test tubes. These were allowed to stand for $30 \mathrm{~min}$. in a dark chamber at room temperature. A standard solution of antioxidant (ascorbic acid) was treated in the same manner and incubated as well together with a reagent blank. At the end of the incubation process, the absorbance of the standard and extract was read with a spectrophotometer. Ability to decolourize DPPH was measured against blank at a wavelength of $517 \mathrm{~nm}$. Percentage inhibition was then calculated thus:

$$
\% \text { Inhibition }=\frac{(\text { Abs Blank }- \text { Abs sample }) \times 100}{\text { Abs Blank }}
$$

where Abs blank, absorbance of blank; Abs sample, absorbance of the sample.

\section{Determination of nitric oxide scavenging activity}

The methods of Panda et al. (2009) and Alisi and Onyeze (2008) were used to measure the nitric oxide scavenging activity of the plant extracts. $4 \mathrm{ml}$ of the extract was added at different concentrations $(0.5,1.0,1.5,2.0$ and $2.5 \mathrm{mg} / \mathrm{ml}$ ) to $1 \mathrm{ml}$ of sodium nitroprusside (SNP) solution $(5 \mathrm{mM})$ in test tubes, and the mixtures were incubated at $27{ }^{\circ} \mathrm{C}$ for $2 \mathrm{~h}$. An aliquot $(2 \mathrm{ml})$ of the incubated solution was taken and diluted with $1.2 \mathrm{ml}$ of Griess reagent ( $1 \%$ sulfanilamide in $5 \% \mathrm{H}_{3} \mathrm{PO}_{4}$ and $0.1 \%$ naphthyl ethylenediamine-dihydrochloride). The absorbance of the chromophore, which was formed during diazotization of the nitrite with sulfanilamide and subsequent coupling with naphthyl ethylenediamine-dihydrochloride, was immediately read at $550 \mathrm{~nm}$ and compared with the absorbance of standard ascorbic acid. where Abs (control), Absorbance of the control; Abs (sample), absorbance of the extract/standard.

\section{Determination of hydrogen peroxide scavenging activity}

This determination adopted the method of Ngonda (2013). A solution of hydrogen peroxide ( $2 \mathrm{mMol} / \mathrm{l})$ was prepared in phosphate buffer ( $\mathrm{pH} 7.4)$. Different concentrations of the extracts $(0.5,1.0,1.5,2.0$ and $2.5 \mathrm{mg} / \mathrm{ml})$ were each added to hydrogen peroxide solution $(0.6 \mathrm{ml})$ in test tubes. The absorbance of hydrogen peroxide at $230 \mathrm{~nm}$ was read after $10 \mathrm{~min}$. against a blank solution (only phosphate buffer) and compared with the standard (ascorbic acid). The hydrogen peroxide activity of the extracts was then calculated using the equation:

$$
\mathrm{H}_{2} \mathrm{O}_{2} \text { activity }(\%)=\frac{\mathrm{Abs}(\text { control })-\mathrm{Abs}(\text { sample })}{\mathrm{Abs}(\text { control })} \times 100
$$

where Abs (control), absorbance of the control; Abs (sample), absorbance of the extracts/standard.

\section{Determination of reducing power}

The reducing power of the plant's extracts was determined using the ferric reducing antioxidant power (FRAP) assay as recorded by Sofidiya et al. (2006). Various concentrations $(0.5,1.0,1.5,2.0$, and $2.5 \mathrm{mg} / \mathrm{ml})$ of the extracts were each added to $1 \mathrm{ml}$ of deionized water and were mixed with $2.5 \mathrm{ml}$ of $0.2 \mathrm{M}$ phosphate buffer (pH 6.6) and $2.5 \mathrm{ml}$ of $1 \%$ potassium ferrocyanide. The mixture was left to incubate at $50^{\circ} \mathrm{C}$ for $20 \mathrm{~min}$. Then, $2.5 \mathrm{ml}$ of $10 \%$ trichloroacetic acid was added and it was centrifuged at $3000 \mathrm{rpm}$ for $10 \mathrm{~min}$. Thereafter, $2.5 \mathrm{ml}$ of the decant was mixed with $0.5 \mathrm{ml}$ of $0.1 \% \mathrm{FeCl}_{3}$. Absorbance was measured at $700 \mathrm{~nm}$. The reducing power of the extracts was determined from the graph of optical density against the concentration of the extracts. Reducing power (RP 0.5 $\mathrm{AU}$ ) was determined as the concentration that gave a 0.5 absorbance reading.

\section{Data analyses}

Data obtained were expressed as mean \pm standard error of the mean (SEM) and analyzed using analysis of Variance (ANOVA) procedure (statistical analysis system (SAS) package version 20 software). Mean differences were subjected to Duncan's multiple range test (DMRT) at a significant difference of $p<0.05$. For in vitro antioxidant activities, the inhibition data (mean values

$$
\text { Nitric oxide scavenging activity }(\%)=\frac{\operatorname{Abs}(\text { control })-\operatorname{Abs}(\text { sample })}{\operatorname{Abs}(\text { control })} \times 100
$$


from triplicate determinations) were fitted into kinetic Eqs. (2-5) which include sigmoid ABC, logistic doseresponse $A B C, A B C D$ and Weibull cumulative $A B C D$ models, respectively, using 2D Systat version 5.01, USA and Sigma plot 10. 0 Systat USA. Percentage inhibition was calculated relative to control using Eq. 1.

\section{Equations}

$$
\% \text { Inhibition }=\left[\frac{\text { Control }_{\mathrm{ABS}}-\text { Test }_{\mathrm{ABS}}}{\text { Control }_{\mathrm{ABS}}}\right] \times 100
$$

Sigmoid a, b, c model

$$
\begin{aligned}
& y=\frac{a}{1+\exp \left(-\left(\frac{x-x_{0}}{b}\right)\right)} \\
& y=\frac{a}{1+\left(\frac{x}{b}\right)^{c}} \\
& y=a+\frac{b}{1+\left(\frac{x}{c}\right)^{d}} \\
& y=a\left[1-\exp \left[-\left[\frac{x+c(\operatorname{In} 2)^{1 / d}-b}{c}\right]^{d}\right]\right]
\end{aligned}
$$

\section{Results}

\section{Phytochemical screening}

Phytochemical analysis of methanol and aqueous extracts of leaves, roots and stem of $C$. dependens showed the presence of tannins, saponins, alkaloids, cardiac glycosides, terpenoids, steroids, phenols, flavonoids, phytate and oxalate (Table 1). Alkaloids and phenols were not detected in the aqueous extract of the stem (Table 1).

\section{In vivo antimalarial test}

From the results obtained, administration of the extracts significantly reduced $(p<0.05)$ parasite count in all animals in the treated groups when compared to the negative control (group 2) whose percentage parasitemia significantly increased (Table 2). By the 14th day (7 days post-treatment), results obtained revealed that percentage parasitemia further reduced significantly $(p<0.05)$ in the treated groups but increased in the untreated control group. When compared to the standard antimalarial drug (artesunate), results obtained from the plant extracts were lower. Among the extracts, the methanol extract of the root of this plant showed the highest antimalarial activity. This extract reduced parasitemia from $75.2 \%$ on day 3 to $27.6 \%$ on day 14 (Table 2). In the negative control group, the percentage of parasitemia increased from $63.0 \%$ on day 3 to $79.2 \%$ on day 14 . The bodyweight of animals in this group was also reduced (Table 3). Antimalarial activity observed in the methanol extract of the leaves of this plant differed significantly $(p<0.05)$ from that of the aqueous extract of the same plant part. Although methanol and aqueous extracts of the leaves, stem and roots of $C$. dependens significantly reduced the percentage of parasitemia in the treated animals, they did

\begin{tabular}{|c|c|c|c|c|c|c|c|}
\hline Phytochemical & Specific test & CDLM & CDSM & CDRM & CDLA & CDSA & CDRA \\
\hline Tannins & Ferric chloride test & + & + & + & + & + & + \\
\hline Saponins & & + & + & + & + & + & + \\
\hline Alkaloids & $\begin{array}{l}\text { Wagner's test } \\
\text { Dragendorff's test }\end{array}$ & + & + & + & + & ND & + \\
\hline $\begin{array}{l}\text { Cardiac } \\
\text { Glycosides }\end{array}$ & Keller-Killani test & + & + & + & + & + & + \\
\hline Terpenoids & Salkowski test & + & + & + & + & + & + \\
\hline Steroids & Liebermann-Burchard test & + & + & + & + & + & + \\
\hline Phenols & Ferric chloride test & + & + & + & + & ND & + \\
\hline Flavonoids & Sodium hydroxide test & + & + & + & + & + & + \\
\hline Oxalate & Oxalate test & + & + & + & + & + & + \\
\hline Phytate & Colourimetric test & + & + & + & + & + & + \\
\hline
\end{tabular}
not completely clear the parasites in these treated groups as shown in Table 2.

Table 1 Qualitative phytochemical analysis of crude aqueous and methanol extracts of the leaves, roots and stems of Chasmanthera dependens

+, present; ND, not detected; CDRM, C. dependens root methanol; CDLM, C. dependens leaves methanol; CDSM, C. dependens stem methanol; CDRA, C. dependens root aqueous; CDLA, C. dependens leaves aqueous; CDSA, C. dependens stem aqueous 
Table 2 In vivo antimalarial activities of crude aqueous and methanolic extracts of the roots, leaves and stems of Chasmanthera dependens on the percentage parasitemia of Plasmodium berghei infected male Swiss albino mice

\begin{tabular}{|c|c|c|c|c|}
\hline \multirow[t]{2}{*}{ Groups/Extracts } & \multicolumn{2}{|r|}{ Average \% } & \multicolumn{2}{|l|}{ Parasitemia } \\
\hline & $\begin{array}{l}\text { Before inoculation } \\
\text { (Day 0) }\end{array}$ & $\begin{array}{l}\text { Before treatment } \\
\text { (Day 3) }\end{array}$ & $\begin{array}{l}\text { After treatment } \\
\text { (Day 7) }\end{array}$ & $\begin{array}{l}\text { After } \\
\text { treatment } \\
\text { (Day 14) }\end{array}$ \\
\hline 1. NC & 0.00 & 0.00 & 0.00 & 0.00 \\
\hline 2. STD.C & 0.00 & 69.0 & 4.6 & 0.00 \\
\hline 3. NEG.C & 0.00 & 63.0 & 72.4 & 79.2 \\
\hline 4. CDRM & 0.00 & 75.2 & 40.6 & 27.6 \\
\hline 5. CDLM & 0.00 & 68.2 & 40.2 & 30.2 \\
\hline 6. CDSM & 0.00 & 73.2 & 57.4 & 47.0 \\
\hline 7. CDRA & 0.00 & 67.0 & 42.8 & 31.2 \\
\hline 8. CDLA & 0.00 & 76.2 & 50.0 & 39.0 \\
\hline 9. CDSA & 00.00 & 76.4 & 61.4 & 49.4 \\
\hline
\end{tabular}

NC, normal control; NEG.C, negative control; STD.C, standard control; CDRM, C. dependens root methanol; CDLM, C. dependens leaves methanol; CDSM, C. dependens stem methanol; CDRA, C. dependens root aqueous; CDLA, C. dependens leaves aqueous; CDSA, C. dependens stem aqueous

Table 3 Effects of crude aqueous and methanolic extracts of leaves, stem and roots of Chasmanthera dependens on percentage body weight and rate of survival of Plasmodium berghi infected male Swiss albino mice

\begin{tabular}{lllllc}
\hline Groups/Extracts & $\begin{array}{l}\text { Number of } \\
\text { animals }\end{array}$ & $\begin{array}{l}\text { Initial body weight of } \\
\text { animals (g) }\end{array}$ & $\begin{array}{l}\text { Final body weight of } \\
\text { animals (g) }\end{array}$ & $\begin{array}{l}\text { \% Body weight of } \\
\text { animals }\end{array}$ & $\begin{array}{l}\text { \% Survival rate } \\
\text { 1. NC }\end{array}$ \\
2. NEG.C & 6 & 23.0 & 26.7 & 16.1 & 100 \\
3. STD.C & 6 & 20.0 & 17.5 & 12.5 & 33.3 \\
4. CDRM & 6 & 18.0 & 20.8 & 15.6 & 100 \\
5. CDLM & 6 & 22.0 & 24.3 & 10.5 & 100 \\
6. CDSM & 6 & 22.0 & 24.1 & 9.6 & 100 \\
7. CDRA & 6 & 25.0 & 26.7 & 6.8 & 50 \\
8. CDLA & 6 & 24.0 & 26.4 & 10.0 & 100 \\
9. CDSA & 6 & 25.0 & 27.0 & 8.0 & 83.3 \\
\hline
\end{tabular}

NC, normal control; NEG.C, negative control; STD.C, standard control; CDRM, C. dependens root methanol; CDLM, C. dependens leaves methanol; CDSM, C. dependens stem methanol; CDRA, C. dependens root aqueous; CDLA, C. dependens leaves aqueous; CDSA, C. dependens stem aqueous

\section{Radical scavenging activities of the extracts}

\section{against 2,2-diphenyl-1-picryihydrazyl (DPPH)}

Activities of the extracts of $C$. dependens were dosedependent in the scavenging of DPPH radicals. Aqueous extract of the root of this plant showed the highest activity, with an $\mathrm{IC}_{50}$ value of $1.10 \pm 0.12 \mathrm{mg} / \mathrm{ml}$ (Table 4). DPPH radical scavenging activities of the extracts were significantly $(p<0.05)$ lower than that of the standard antioxidant whose $\mathrm{IC}_{50}$ value was $0.58 \pm 0.05 \mathrm{mg} / \mathrm{ml}$. Results obtained from this study show that the DPPH radical scavenging property of the aqueous and methanol extracts was also largely sigmoidal (Table 4). Figure 2 shows the effects of crude aqueous and methanol extracts of leaves, stem and roots of $C$. dependens and ascorbic acid (AA) on scavenging of 2,2-diphenyl-1-picrylhydrazyl (DPPH) radical.
Nitric oxide scavenging activities of the extracts

Nitric oxide radical scavenging activities of crude aqueous and methanol extracts of leaves, stem and roots of $C$. dependens and ascorbic acid (AA) standard are shown in Table 5. Results obtained show that methanol extracts scavenged more than the aqueous extracts as shown in their $\mathrm{IC}_{50}$ values evaluated from the inhibition graph (Fig. 3). Activities of the extracts were however significantly $(p<0.05)$ lower than that of the standard. Results presented in Fig. 3 show the ability of extracts to scavenge nitric oxide, generated in vitro by sodium nitroprusside, followed by a sigmoid $A B C$ model. 
Table 4 Threshold Inhibitory concentration $\left(\mathrm{IC}_{50}\right)$ of crude aqueous and methanolic extracts of leaves, stem and roots of $C$. dependens and ascorbic acid standard on DPPH radicals

\begin{tabular}{|c|c|c|c|c|}
\hline Extracts & Threshold inhibitory concentration $\left({ }^{*} \mid C_{50}\right)$ & Mathematical model & Equation & $R^{2}$ \\
\hline CDRM & $1.81 \pm 0.32$ & Sigmoid $(a, b, c)$ & $y=\frac{}{1+\exp }$ & 0.941 \\
\hline CDLM & $1.44 \pm 0.14$ & Sigmoid $(a, b, c)$ & $y=\frac{}{1+\exp }$ & 0.956 \\
\hline CDSM & $1.52 \pm 0.10$ & Sigmoid $(a, b, c)$ & $y=\frac{}{1+\exp }$ & 0.975 \\
\hline CDRA & $1.10 \pm 0.12$ & Sigmoid $(a, b, c)$ & $y=\frac{}{1+\exp }$ & 0.939 \\
\hline CDLA & $1.81 \pm 0.32$ & Sigmoid $(a, b, c)$ & $y=\overline{1+\exp }$ & 0.942 \\
\hline CDSA & $1.51 \pm 0.14$ & Sigmoid $(a, b, c)$ & $y=\frac{}{1+\exp }$ & 0.966 \\
\hline AA & $0.58 \pm 0.05$ & Sigmoid $(a, b, c)$ & $y=\frac{}{1+\exp }$ & 0.934 \\
\hline
\end{tabular}

CDRM, C. dependens root methanol; CDLM, C. dependens leaves methanol; CDSM, C. dependens stem methanol; CDRA, C. dependens root aqueous; CDLA, C. dependens leaves aqueous; CDSA, C. dependens stem aqueous; $A$ A, ascorbic acid

${ }^{*} \mathrm{C}_{50}$ is the concentration of extract or standard that scavenged $50 \%$ of the generated free radicals

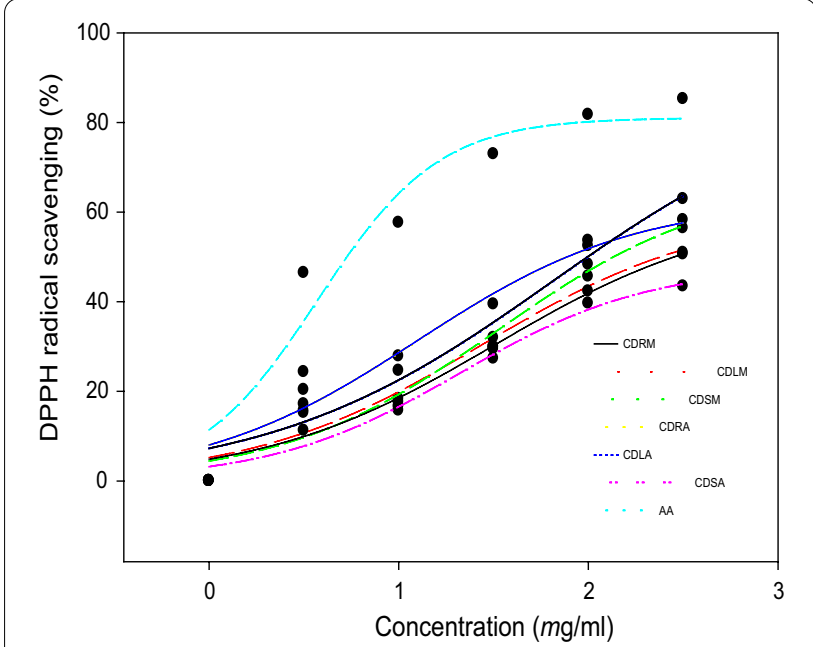

Fig. 2 Effects of crude aqueous and methanol extracts of leaves, stem and roots of $C$. dependens and ascorbic acid (AA) on scavenging of 2,2-diphenyl-1-picrylhydrazyl (DPPH) radical

Effects of crude aqueous and methanol extracts of leaves, stem and roots of $C$. dependens and ascorbic acid on scavenging hydrogen peroxide $\left(\mathrm{H}_{2} \mathrm{O}_{2}\right)$ radical

Table 6 shows the hydrogen peroxide radical scavenging activities of $C$. dependens and ascorbic acid (AA) standard. Result obtained also shows that scavenging activities of the extracts were largely sigmoidal, while the standard antioxidant followed a logistic dose-dependent pattern. Inhibitory effects of the extracts against hydrogen peroxide radicals were comparable to the standard. Hydrogen peroxide radical scavenging activity of leaves, stem and roots of $C$. dependens was in the order $\mathrm{AA}>\mathrm{CDSA}>\mathrm{CDRA}>\mathrm{CDRM}$ $>\mathrm{CDLA}>\mathrm{CDSM}>\mathrm{CDLM}$. Figure 4 shows the hydrogen peroxide radical scavenging activities of crude aqueous and methanol extracts of leaves, stem and roots of $C$. dependens and Ascorbic acid.

\section{Ferric reducing antioxidant power of crude aqueous and methanolic extracts of leaves, stem and roots of Chasmanthera dependens}

Figure 5 shows the Ferric reducing antioxidant power of crude aqueous and methanolic extracts of $C$. dependens and ascorbic acid. The result obtained from the study shows that ascorbic acid was a more potent reducing agent with $\mathrm{RP}_{0.5}=0.18 \mathrm{mg} / \mathrm{ml}$. Results show that the root of $C$. dependens in methanolic solvent possesses reducing power activity $(0.41 \pm 0.05)$ comparable to the standard. Results obtained from extracts demonstrated a logistic dose-dependent response reducing effect on ferric chloride by AA, CDRM, and CDLA, CDLM followed a Weibull cumulative ( $a, b, c, d$ ) model, while the reducing power of CDSA, CDSM and CDRA was sigmoidal (Sigmoid a, b, c) as shown in Table 7.

\section{Discussion}

Extraction yield (\% w/w) is a measure of the efficiency of a solvent to extract particular components from the original material. Aqueous (water) and methanol solvents were used for extraction in this study following a folkloric practice. Extract yield (\% of dry wt.) from the studied 
Table 5 Threshold inhibitory concentration $\left(\mathrm{IC}_{50}\right)$ of crude aqueous and methanolic extracts of leaves, stem and roots of $C$. dependens and ascorbic acid standard on nitric oxide radicals

\begin{tabular}{llll}
\hline Extracts & Threshold inhibitory concentration $\left({ }^{*} \mathbf{C}_{50}\right)$ & Mathematical model & Equation \\
\hline CDRM & $1.16 \pm 0.12$ & Sigmoid $(a, b, c)$ & $y=\frac{a}{1+\exp \left(-\left(\frac{x-x_{0}}{b}\right)\right)}$ \\
CDLM & $1.10 \pm 0.11$ & Sigmoid $(a, b, c)$ & $y=\frac{a}{1+\exp \left(-\left(\frac{x-x_{0}}{b}\right)\right)}$ \\
CDSM & $1.25 \pm 0.26$ & Sigmoid $(a, b, c)$ & $y=\frac{a}{1+\exp \left(-\left(\frac{x-x_{0}}{b}\right)\right)}$ \\
CDRA & $1.32 \pm 0.14$ & Sigmoid $(a, b, c)$ & $y=\frac{a}{1+\exp \left(-\left(\frac{x-x_{0}}{b}\right)\right)}$ \\
CDLA & $1.62 \pm 0.24$ & Sigmoid $(a, b, c)$ & $y=\frac{a}{1+\exp \left(-\left(\frac{x-x_{0}}{b}\right)\right)}$ \\
CDSA & $1.36 \pm 0.22$ & Sigmoid $(a, b, c)$ & $y=\frac{a}{1+\exp \left(-\left(\frac{x-x_{0}}{b}\right)\right)}$ \\
AA & $0.65 \pm 0.07$ & Sigmoid $(a, b, c)$ & $y=\frac{a}{1+\exp \left(-\left(\frac{x-x_{0}}{b}\right)\right)}$
\end{tabular}

CDRM, C. dependens root methanol; CDLM, C. dependens leaves methanol; CDSM, C. dependens stem methanol; CDRA, C. dependens root aqueous; CDLA, C. dependens leaves aqueous; $C D S A, C$. dependens stem aqueous; $A A$, ascorbic acid

${ }^{*} I C_{50}$ is the concentration of extract or standard that scavenged $50 \%$ of the generated free radicals

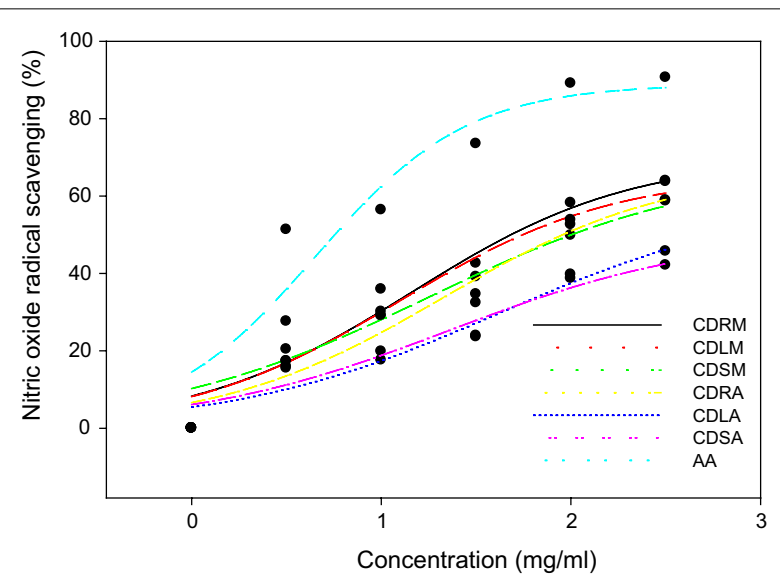

Fig. 3 Nitric oxide radicals scavenging activities of crude aqueous and methanol extracts of leaves, stem and roots of $C$. dependens and ascorbic acid standard

plant was higher in the organic extracts (methanol) than in the aqueous extracts, which agrees with the findings of Pareck et al. (2015) that phytochemicals in plants are more soluble in organic compounds. The difference in yield may have been due to the polarity of the extracted compounds. The low polarity of methanol was probably accountable for the high yield of extracts because both polar and non-polar compounds were extracted. Results also suggest that crude powder extracts obtained from $C$. dependens could be affected by the extracting solvents.

Antimalarial activities were high in the roots and leaves and least in the stem of $C$. dependens (Tables 2,3). Other in vivo studies in mice revealed significant antimalarial activities in the roots of studied plants (Andrade-Neto et al. 2013; Murti and Mishra 2014). Leaves and roots of medicinal plants are extensively used in herbal remedies (Andrade-Neto et al. 2013). Methanol and aqueous extracts of the stem of $C$. dependens exhibited the least antimalarial activity on Plasmodium berghei infected mice. This could be attributed to the nature of the stem which is not woody, confirming an earlier report that plants with significant antimalarial activities in their stem extracts are trees with stem bark (Muthaura et al. 2017). Although antimalarial activities of methanol extracts of the leaves, roots and stem of $C$. dependens were more than that of the aqueous extracts, there was no significant difference except methanol extract of the leave which significantly $(p<0.05)$ differed from the aqueous extract. This confirmed an earlier report that bioactive constituents are more soluble in methanol than in the aqueous medium (Pareck et al. 2015). Unlike the standard antimalarial drug (artesunate), extracts from this plant did not achieve total eradication of the parasites. Standard antimalarial drugs are more effective but they are not readily available and they are sold at exorbitant prices, justifying the use of these herbs and medicinal plants (Mgbemena et al. 2010).

An increase in body weight was recorded in the infected and treated animals (Table 3), which could be attributed to the efficacy of the extracts on Plasmodium berghei infected mice. A decrease in percentage (\%) body weight recorded in the untreated animals could be as a result of the parasites feeding on the blood cells of 
Table 6 Threshold inhibitory concentration $\left(\mathrm{IC}_{50}\right)$ of crude aqueous and methanol extracts of $\mathrm{C}$. dependens and ascorbic acid standard on hydrogen peroxide radicals

\begin{tabular}{|c|c|c|c|c|}
\hline Extracts & Threshold inhibitory concentration $\left({ }^{*} \mid C_{50}\right)$ & Mathematical model & Equation & $R^{2}$ \\
\hline CDRM & $0.90 \pm 0.09$ & Sigmoid $(a, b, c)$ & $y=\frac{a}{1+\exp \left(-\left(\frac{x-x_{0}}{b}\right)\right)}$ & 0.931 \\
\hline CDLM & $1.17 \pm 0.17$ & Sigmoid $(a, b, c)$ & $y=\frac{a}{1+\exp \left(-\left(\frac{x-x_{0}}{b}\right)\right)}$ & 0.920 \\
\hline CDSM & $1.16 \pm 0.15$ & Sigmoid $(a, b, c)$ & $y=\frac{a}{1+\exp \left(-\left(\frac{x-x_{0}}{b}\right)\right)}$ & 0.915 \\
\hline CDRA & $0.71 \pm 0.07$ & Sigmoid $(a, b, c)$ & $y=\frac{a}{1+\exp \left(-\left(\frac{x-x_{0}}{b}\right)\right)}$ & 0.915 \\
\hline CDLA & $0.93 \pm 0.11$ & Sigmoid $(a, b, c)$ & $y=\frac{a}{1+\exp \left(-\left(\frac{x-x_{0}}{b}\right)\right)}$ & 0.911 \\
\hline CDSA & $0.59 \pm 0.11$ & Sigmoid $(a, b, c)$ & $y=\frac{a}{1+\exp \left(-\left(\frac{x-x_{0}}{b}\right)\right)}$ & 0.810 \\
\hline AA & $0.38 \pm 0.01$ & $\begin{array}{l}\text { Logistic dose response }(a, \\
b, c)\end{array}$ & $y=\frac{a}{1+\left(\frac{x}{b}\right)^{c}}$ & 0.999 \\
\hline
\end{tabular}

CDRM, C. dependens root methanol; CDLM, C. dependens leaves methanol; CDSM, C. dependens stem methanol; CDRA, C. dependens root aqueous; CDLA, C. dependens leaves aqueous; CDSA, C. dependens stem aqueous; AA, ascorbic acid

${ }^{*} \mathrm{C}_{50}$ is the concentration of extract or standard that scavenged $50 \%$ of the generated free radicals

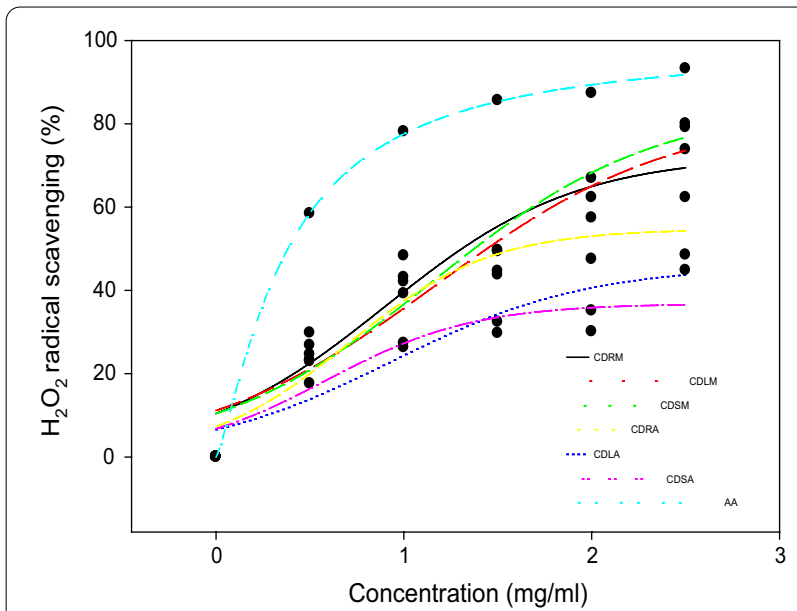

Fig. 4 Hydrogen peroxide radical scavenging activities of crude aqueous and methanol extracts of leaves, stem and roots of $C$. dependens and ascorbic acid standard

the experimental animals bringing about a reduction in their body weight. This agrees with the reports of Ene et al. (2013). The survival rate of animals in the treatment groups indicated that extracts used in this study were not toxic to the experimental animals at the administered doses. Phytochemical constituents have been reported to have varying degrees of therapeutic activities (Gupta and Tandon 2014). The presence and therapeutic activities of phytochemicals in this plant could be accountable for the observed antimalarial activities of different parts of $C$. dependens as observed in the study.

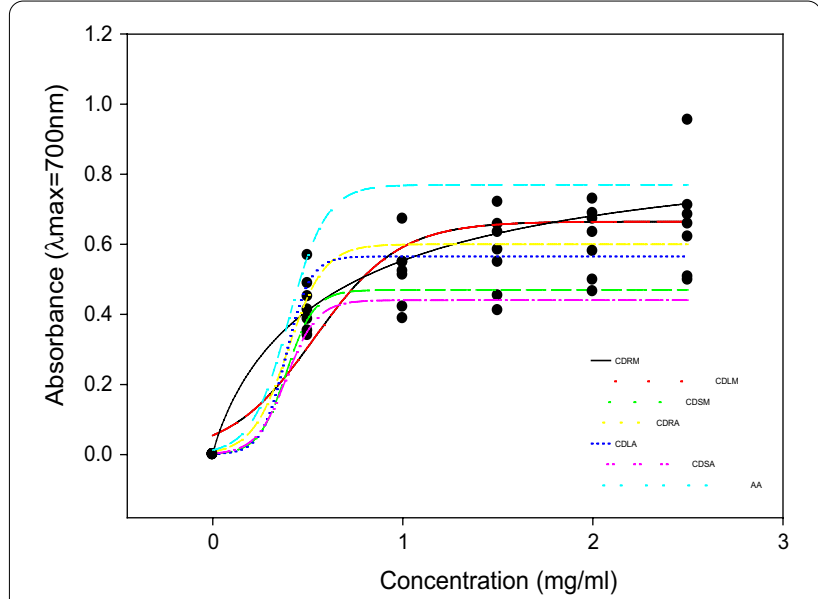

Fig. 5 Ferric reducing antioxidant power (FRAP) of crude aqueous and methanolic extracts of leaves, stem and roots of Chasmanthera dependens and ascorbic acid

The therapeutic properties of plants are credited to the antioxidant compounds and phytochemicals present in these medicinal plants (Padmanabhan and Jangle 2012). Antioxidants are known for their ability to scavenge free radicals, ameliorate free radical related diseases and conditions, such as oxidative stress. Extracts of the leaves, stem and roots of $C$. dependens showed appreciable antioxidant activities. Aqueous and methanolic extracts of the leaves, stem and roots of $C$. dependens showed DPPH scavenging activities in a concentration dependent-manner with DPPH scavenging activities increasing with an 
Table 7 Ferric reducing antioxidant power (FRAP) of crude aqueous and methanolic extracts of leaves, stem and roots of Chasmanthera dependens and ascorbic acid

\begin{tabular}{lllll}
\hline Extracts & Reducing power $\left(\mathbf{R P}_{0.5}\right)$ & Mathematical model & Equation & $\boldsymbol{R}^{\mathbf{2}}$ \\
\hline CDRM & $0.41 \pm 0.05$ & Logistic dose response $(\mathrm{a}, \mathrm{b}, \mathrm{c})$ & $y=\frac{a}{1+\left(\frac{x}{b}\right)^{c}}$ & 0.992 \\
CDLM & $0.52 \pm 0.07$ & WeibullCum $(a, b, c, d)$ & $y=a\left[1-\exp \left[-\left[\frac{x+c(\ln 2)^{1 / d}-b}{c}\right]^{d}\right]\right]$ & 0.998 \\
CDSM & $2.26 \pm 0.11$ & Sigmoid $(a, b, c)$ & $y=\frac{a}{1+\exp \left(-\left(\frac{x-x_{0}}{b}\right)\right)}$ \\
CDRA & $0.54 \pm 0.05$ & Sigmoid $(a, b, c)$ & $y=\frac{a}{1+\exp \left(-\left(\frac{x-x_{0}}{b}\right)\right)}$ \\
CDLA & $0.73 \pm 0.04$ & Logistic dose response $(a, b, c)$ & $y=\frac{a}{1+\left(\frac{x}{b}\right)^{c}}$ & 0.973 \\
CDSA & $2.67 \pm 0.23$ & Sigmoid (a, b, c) & $y=\frac{a}{1+\exp \left(-\left(\frac{x-x_{0}}{b}\right)\right)}$ \\
AA & $0.18 \pm 0.00$ & Logistic dose response $(a, b, c)$ & $y=\frac{a}{1+\left(\frac{x}{b}\right)^{c}}$
\end{tabular}

CDRM, C. dependens root methanol; CDLM, C. dependens leaves methanol; CDSM, C. dependens stem methanol; CDRA, C. dependens root aqueous; CDLA, C. dependens leaves aqueous; CDSA, $C$. dependens stem aqueous; $A A$, ascorbic acid

increase in the concentration of extracts. This agrees with the report of Gyamfi et al. (1999). The high reduction in DPPH as recorded in this study is related to the high scavenging activity of a particular sample (Asadu et al. 2018).

Despite the beneficial effects of nitric oxide, it contributes to oxidative damage. This is because NO can react with superoxide ions to form a peroxynitrite anion which is a strong oxidant that can decompose to produce $\mathrm{OH}$ and $\mathrm{NO}_{2}$ (Alisi et al. 2018). The present study showed that aqueous and methanolic extracts of leaves, stem and roots of $C$. dependens have potent nitric oxide scavenging activities, efficiently converting nitric oxide to nitrites. Nitric oxide scavenging activities recorded in this study could be attributed to secondary metabolites, such as tannins, saponnins, flavonoids and carotenoids present in these plant extracts which agrees with Molyneux (2014).

This study also showed that aqueous and methanolic extracts of the leaves, stem and roots of $C$. dependens scavenged hydrogen peroxide $\left(\mathrm{H}_{2} \mathrm{O}_{2}\right)$ effectively, compared to Ascorbic acid (standard antioxidant). Hydrogen peroxide $\left(\mathrm{H}_{2} \mathrm{O}_{2}\right)$ easily decomposes into oxygen and water which may produce hydroxyl $(\mathrm{OH})$ radicals that can initiate lipid peroxidation causing damage to DNA. Scavenging of $\mathrm{H}_{2} \mathrm{O}_{2}$ by extracts of $C$. dependens could be attributed to the presence of phenols which can donate electrons to $\mathrm{H}_{2} \mathrm{O}_{2}$ and neutralize it to water. Ferric reducing antioxidant power ability of extracts indicates the presence of reducing agents whose atoms can donate electrons or react with free radicals and convert them into stable metabolites, terminating radical chain reactions (Toykuni 2019). The plant extracts possession of ferric reducing antioxidant power also indicated the ability of the bioactive components present in the plant extracts to donate hydrogen. This equally agrees with Shidduraju et al. (2012) that the ferric reducing power of most biologically active compounds is linked with antioxidant activity.

\section{Conclusions}

From this study, methanol and aqueous extracts of the leaves, roots and stem of $C$. dependens possess antimalarial activities and antioxidant activities. Methanol extracts of leaves and roots were however more effective on Plasmodium berghei infected animals. Findings from this study also showed that both solvents used in the study are good for the extraction of antimalarial and antioxidant compounds from the plant parts. This study, therefore, supports the continued use of this plant in ethnomedicine for the management of malaria. This research equally revealed that these plants could be potential sources of natural antioxidants, preventing and/or slowing degenerative diseases. However, more work is required to identify and characterize antimalarial and antioxidant compounds from the leaves and roots of this plant.

\section{Abbreviations}

mg/kg: Milligram/kilogram; b.wt.: Body weight; $\mathrm{H}_{2} \mathrm{O}_{2}$ : Hydrogen peroxide; $\mathrm{NO}$ : Nitric oxide; DPPH: 2,2 Diphenyl-1-picryl hydrazyl radical; AA: Ascorbic acid.

\section{Acknowledgements}

We are grateful to TETFUND IBRF for sponsoring this research. We also thank Dr M.C Duru of the Department of Biology, Federal University of Technology, Owerri, Nigeria, for his assistance in the identification and authentication of the plant materials. We also thank Mrs Pauline Azode who assisted us in collecting the plant. We equally acknowledge the Department of Biochemistry, University of Nigeria, Nsukka for their facilities. 


\section{Authors' contributions}

CKE designed the study; UEE gathered the plant materials, conducted the experiment and prepared the manuscript; CEO, IAD and SOA supervised the research work; $\mathrm{CON}$ and $\mathrm{MO}$ carried out data analysis the data while OIO helped with the literature search. All authors read, corrected and approved the manuscript and gave consent to submit the manuscript for publication in Bulletin of the Natural Research Centre. All authors read and approved the final manuscript.

\section{Availability of data and materials}

Data sharing does not apply to this article as no datasets were generated or analyzed during the current study.

\section{Declarations}

\section{Ethics approval and consent to participate}

The animals used for the experiment were handled following NIH guide for the care and use of laboratory animals Standard operating manual of NIPRD, approved by the Research Ethics Committee of Department of Biochemistry, Federal University of Technology, Owerri, Nigeria with the reference number-FUTO/BCH/DEC/XXI/03/01.

\section{Consent for publication}

Not applicable.

\section{Competing interests}

The authors declare that they have no competing interests.

\section{Author details}

'Department of Chemistry, Federal University of Technology Owerri, Owerri, Nigeria. ${ }^{2}$ Department of Microbiology, Federal University of Technology Owerri, Owerri, Nigeria. ${ }^{3}$ Department of Biotechnology, Federal University of Technology Owerri, Owerri, Nigeria. ${ }^{4}$ Department of Mathematics, Federal University of Technology Owerri, Owerri, Nigeria. ${ }^{5}$ Department of Biochemistry, Federal Polytechnic, Ekowe, Bayelsa State, Nigeria.

Received: 26 December 2021 Accepted: 3 February 2022

Published online: 16 February 2022

\section{References}

Adebayo JO, Kareth AU (2010) Potential anti-malarial from Nigeria plants, a review. J Ethnopharmacol 133:289-302

Adekunle AA, Okoli SO (2002) Antifungal activities of the crude extracts of Alafia barteri Oliver (Apocynaceae) and Chasmanthera dependens (Hochst). Menispermaceae Hamdard Med Pak 45(3):52-56

Alisi CS, Onyeze GOC (2008) Nitric oxide scavenging ability of ethyl acetate fraction of methanolic leaf extracts of Chromolaena odorata (Linn.). Afr J Biochem Res 2(7):145-150

Alisi CS, Asiwe ES, Ene CA, Alisi PN (2018) Antioxidant and free radical scavenging properties of aqueous extract of Psidium guajava leaf. FUTO $\mathrm{J}$ Ser 4(1):222-234

Aluko BT, Oloyede OI, Afolayan AJ (2013) Polyphenolic contents and free radical scavenging potential of extracts from leaves of Ocimum americanum L. Pak J Biol Sci 16:22-30

Andrade-Neto VF, Brandao MG, Stehman JR, Oliveira LA, Krettli AU (2013) Antimalarial activity of Cinchona-like plants used to treat fever and malaria in Brazil. J Ethnopharmacol 87:253-256

Asadu CL, Abonyi O, Anosike CA, Uzoegwu PN, Uroko R (2018) In vivo toxicological studies on methanol leaf extract of Lantana Camara. Am Eurasian J Toxicol Sci 7(2):115-122

David AF, Philip JR, Simon RC, Solomon N (2004) Antimalarial drug discovery: efficacy models for compound screening. Nat Revolut 3:509-520

David AF, Philip JR, Simon RC, Reto B, Solomon N (2014) Antimalarial drug discovery; efficiency models for compound screening. Nat Rev 3:509-520

Dejen N, Assefa S, Teshome N, Engidawork E (2018) In vivo Antimalarial Activity of the $80 \%$ methanolic root bark extract and solvent fractions of Gardenia ternifolia Schumac. \& Thonn. (Rubiaceae) against Plasmodium berghei. Evid Based Complement Altern Med 11:1-10
Ene AC, Obika CJ, Okwu GN, Alisi CS, Edeh NG (2013) In vivo anti-malarial effect of methanol and aqueous extracts of Picralima nitida plant parts. J Res Biochem 1(2):095-105

Githinji EK, Irungu LW, Tonia WK, Rukuga GM, Mutai C, Mathaura CN, Wanjoya A (2010) In vitro effects of Warburgia ugandensis, Psidia puntulata and Chasmanthera dependens on Leishmania major promastigotes. Afr J Tradit Complement Altern Med 7(3):264-275

Gupta AK, Tandon N (2014) Therapeutic values of secondary metabolites from plants. Rev Indian Med Plants 1:33-39

Gyamfi MA, Yonamine M, Aniya Y (1999) Free-radical scavenging action of medicinal herbs from Ghana: Thonningia sanguine on experimentallyinduced liver injuries. Gen Pharmacol 32:661-667

Harborne JB (1973) Phytochemical methods: a guide to modern techniques on plant analysis. Chapman and Hall, London, pp 279-281

Ifeanyichukwu US, Chukwunonso JP, Elisha D (2016) Economics of broiler production among rural women in Ahiazu Mbaise LGA of Imo State, Nigeria. Asian Res J Agric 1(2):1-8

Iwalewa EO, Lege-Oguntuge L, Rai PP, Iyaniwura TT (1997) In vivo and in vitro antimalarial activity of two crude extracts of Cassia occidentalis leaf. Niger J Pharm Sci 5:23-28

Iwu MD, Duncan AR, Okunji CO (1999) New antimicrobials of plant origin. In: Janick J (ed) Perspectives on new crops and new uses. ASHS Press, Alexandria, pp 457-462

Jayasri MA, Mathew L, Radha A (2019) A report on the antioxidant activities of leaves and rhizomes of Costus pictus D. Don. Int J Integr Biol 5(1):20-26

Kabiru YA, Okolie NL, Muhammad HL, Ogbadoyi EO (2012) Preliminary studies on the antiplasmodial potential of aqueous and methanol extracts of Eucalyptus camadulensis leaf. Asian Pac J Trop Dis 2:S809-S814

Lim YY, Quah ED (2007) Antioxidant properties of different cultivars of Portulaca oleracea. Food Chem 103:734-740

Mgbemena IC, Opara FC, Ukaoma A, Ofodu C, Njoku I, Ogbuagu DH (2010) The prophylactic potential of lemon grass and neem as antimalarial agents. J Am Sci 6:8

Molyneux P (2014) The use of the stable free radical diphenylpicrylhydrazyl (DPPH) for estimating antioxidant activity. Songklanakarin J Sci Technol 26:211-219

Moody CM, Chua B, Weary DM (2014) The effect of carbon dioxide flow rate on the euthanasia of laboratory mice. Lab Animals 48(4). https://doi.org/10. $1177 / 0023677214546509$

Morebise O, Awe EO, Makinde JM, Olajide AO (2001) Evaluation of the antiinflammatory and analgesic properties of Chasmanthera dependens leaf methanol extract. Fitoterapia 72:497-502

Murti Y, Mishra P (2014) Synthesis and evaluation of flavones as antimalarial agents. Indian J Pharm Sci 76:163-166

Mustofa J, Sholikhah EN, Wahyuono S (2007) In vitro and in vivo antiplasmodial activity and cytotoxicity of extracts of Phyllanthus niruri L. herbs traditionally used to treat malaria in Indonesia. Southeast Asian J Trop Med Public Health 38:609-615

Muthaura CN, Rukunga GM, Chhabra SC, Omar SA, Guantaiu AN, Hathirwa JW, Tola FM, Mwitari PG, Keter LK, Kirira PG, Kimani CW, Munga GW, Njagi ENM (2017) Antimalarial activity of some plants traditionally used in the treatment of malaria in Kwale district of Kenya. J Ethnopharmacol 112(3):545-551

Ngonda F (2013) In-vitro antioxidant activity and free radical scavenging potential of roots of Malawian Trichodesma zeylanicumm (burm. F.). Asian J Biomed Pharm Sci 3(20):21-25

Ogunlesi M, Okiei W, Ademoye M (2008) Medical plants used in treating eye infection in Nigeria. In: Odugbemi T (ed) A textbook of medicinal plants from Nigeria. University of Lagos Press, Lagos, p 304

Okafor FU, Oko-Ose JN (2012) Prevalence of malaria infections among children aged six months to eleven years ( 6 months- 11 years) in Benin City, Nigeria. Glob Adv Res J Med Med Sci 10:273-279

Padmanabhan P, Jangle SN (2012) Evaluation of DPPH radical scavenging activity and reducing the power of four selected medicinal plants and their combinations. Int J Pharm Sci Drug Res 4:143-146

Panda BN, Raj AB, Shrivastava NR, Prathani AR (2009) The evaluation of nitric oxide scavenging activity of Acalypha indica Lin root. Asian J Res Chem 2(2):148-156

Pareck J, Jadeja D, Chanda S (2015) Efficacy of aqueous and methanol extracts of some medicinal plants for potential antibacterial activity. Turk J Biol 29:203-210 
Peter LT, Anatoli, VK (1998) The current global malarial situation. In: Malarial parasite biology, pathogenesis and protection. ASM Press, Washington, DC, pp 11-22

Quadri AL, Yakubu MT (2017) Fertility enhancing activity and toxicity profile of aqueous extract of Chasmanthera dependens roots in male rats. Andrologia 1:4-9

Shidduraju P, Mohan PS, Becker K (2012) Studies on antioxidant activity of Indian Laburnum (Cassia fistula L.): a preliminary assessment of crude extract from stem bark leaves, flower and fruit pulp. Food Chem 79:61-67

Sofidiya MO, Odukoya OA, Familoni OB, Inya-Agha SI (2006) Free radical scavenging activity of some Nigerian Medicinal plant extract. Pak J Biol Sci 9:1438-1441

Sofowora A (1993) Medicinal plants and traditional medicines in Africa. Willey, New York, p 256

Toykuni S (2019) Reactive oxygen species induced molecular damage and its application in pathology. Pathol Int 49:91-102

Trease GE, Evans WC (1989) Pharmacognosy, 13th edn. Bailliere Tindall Ltd, London, pp 132-133

Uddin SN, Akond MA, Mubassara S, Yesmin MN (2018) Antioxidant and antibacterial activities of Trema cannabina. Middle-East J Sci Res 3:105-108

World Health Organisation (2015) Antimalarial drug resistance. http://www. who.int/malaria/areas/drug_resistance/overview/en/. Accessed 13 June 2017

\section{Publisher's Note}

Springer Nature remains neutral with regard to jurisdictional claims in published maps and institutional affiliations.

\section{Submit your manuscript to a SpringerOpen ${ }^{\circ}$ journal and benefit from:}

- Convenient online submission

- Rigorous peer review

- Open access: articles freely available online

- High visibility within the field

- Retaining the copyright to your article

Submit your next manuscript at $\boldsymbol{\nabla}$ springeropen.com 